\title{
Correction to: Phytomining to re-establish phosphorus-poor soil conditions for nature restoration on former agricultural land
}

\author{
Stephanie Schelfhout (D) An De Schrijver • Margot Vanhellemont • Pieter Vangansbeke • \\ Safaa Wasof • Michael P. Perring • Geert Haesaert • Kris Verheyen • Jan Mertens
}

Published online: 10 May 2019

(C) Springer Nature Switzerland AG 2019

\section{Correction to: Plant Soil \\ https://doi.org/10.1007/s11104-019- \\ 04049-2}

In the published version, the author names were presented incorrectly. The forenames and surnames were switched for everyone, except for Michael P Perring. The correct author names are shown here by following the order "forename surname": Stephanie Schelfhout, An De Schrijver, Margot Vanhellemont, Pieter Vangansbeke,

The online version of the original article can be found at https://doi.org/10.1007/s11104-019-04049-2

S. Schelfhout $(\bowtie) \cdot$ A. De Schrijver $\cdot$ P. Vangansbeke • S. Wasof $\cdot$ M. P. Perring $\cdot$ K. Verheyen $\cdot J$. Mertens Forest \& Nature Lab, Department of Environment, Faculty of Bioscience Engineering, Ghent University,

Geraardsbergsesteenweg 267, 9090 Gontrode (Melle), Belgium e-mail: Stephanie.Schelfhout@ugent.be

A. De Schrijver · M. Vanhellemont

Faculty of Science and Technology, University College Ghent, Brusselsesteenweg 161, 9090 Melle, Belgium

M. P. Perring

Ecosystem Restoration and Intervention Ecology (ERIE) Research Group, School of Plant Biology, The University of Western Australia, 35 Stirling Highway, Crawley, WA 6009, Australia

G. Haesaert

Department of Plants and Crops, Faculty of Bioscience Engineering, Ghent University, Valentin Vaerwyckweg 1, 9000 Ghent, Belgium
Safaa Wasof, Michael P Perring, Geert Haesaert, Kris Verheyen, Jan Mertens. We apologize for any inconvenience caused to the readers by these changes.

The original article has been corrected.

Publisher's note Springer Nature remains neutral with regard to jurisdictional claims in published maps and institutional affiliations. 